\title{
Studies of Electrochemical Behavior of SWNT-film Electrodes
}

\author{
M. Muzibur Rahman* and I. Cheol Jeon \\ Laboratory of Interface and Surface Science, Department of Chemistry, \\ Chonbuk National University, Jeonju 561-756, South Korea
}

\begin{abstract}
As reações redox de $4 \mathrm{mmol} \mathrm{L}^{-1}$ da espécie $\mathrm{K}_{4}\left[\mathrm{Fe}(\mathrm{CN})_{6}\right]$ foram estudadas com eletrodo de carbono vítreo (GCE) e eletrodo de ouro (GE) coberto com nanotubo de carbono com parede de camada única (SWNT), e eletrodos de filme de SWNT (tipo filme de papel), individualmente. O eletrodo modificado com SWNT (fisicamente) mostrou um pico redox bem definido, comparando com eletrodos sem cobrimento. A técnica de voltametria cíclica foi utilizada em 50,0 $\mathrm{mmol} \mathrm{L}^{-1}$ $\mathrm{KCl}$ contendo $\mathrm{K}_{4}\left[\mathrm{Fe}(\mathrm{CN})_{6}\right.$ ] para obter informação sobre a contribuição capacitiva e a transferência de carga na reação faradaica, das espécies redox. A capacitância dá uma noção sobre a área superficial efetiva (incluindo a superfície exterior e interior dos eletrodos de ouro e de carbono vítreo coberto-SWNT), assim como sobre a pseudocapacitância devida às reações faradaicas dos óxidos ligados à superfície. Dentre os três tipos de eletrodos, o eletrodo de filme-SWNT apresentou a maior capacitância de volume específico, consistente com sua densidade de empacotamento mais alta e maior área superficial efetiva. Isto indica que o eletrodo de nanotubo de carbono (eletrodo com filme depositado ou tipo papel) comporta-se como um eletrodo tri-dimensional. A reação redox de $\mathrm{Fe}(\mathrm{CN})_{6}^{3-} / \mathrm{Fe}(\mathrm{CN})_{6}{ }^{4}$ foi encontrada não somente na superfície externa do nanotubo de carbono, mas também na superfície interior do eletrodo tipo papel.
\end{abstract}

The redox reactions of $4 \mathrm{mmol} \mathrm{L}^{-1} \mathrm{~K}_{4}\left[\mathrm{Fe}(\mathrm{CN})_{6}\right]$ species have been studied with Single-Walled Carbon Nanotube (SWNT)-coated Glassy Carbon Electrode (GCE), SWNT-coated Gold Electrode (GE) and lab-made SWNT-film (SWNT-Thin-Paper-Like-Film) Electrodes individually. The SWNT-modified (physically) electrode has shown a well-defined redox peak compared with bare electrodes. $\mathrm{CV}$ is used in $50.0 \mathrm{mmol} \mathrm{L}^{-1} \mathrm{KCl}$ containing $\mathrm{K}_{4}\left[\mathrm{Fe}(\mathrm{CN})_{6}\right]$ to obtain information on both the capacitive background and electron transfer from the faradaic reaction of the redox species. The capacitance gives insight into the effective surface area (including both the exterior surface and the interior surface within the SWNT-coated glassy carbon and gold electrodes and SWNT-film electrode) as well as the Pseudocapacitance due to faradaic reactions of surface bonded oxides. Among the three kinds of electrode, the SWNT-film electrode presented the largest volume specific capacitance, consistent with its highest carbon nanotube packing density and largest effective surface area. This indicates that the carbon nanotube-working electrode (whether coated or film electrode) behaves as a three-dimensional electrode. The redox reaction of $\mathrm{Fe}(\mathrm{CN})_{6}^{3-}$ $\mathrm{Fe}(\mathrm{CN})_{6}{ }^{4-}$ was found to occur not only at the outer surface of the carbon nanotube but also at the interior surface of the thin paper like nanotube electrode.

Keywords: SWNT-film electrode, SWNT-coated GCE, SWNT-coated GE, cyclic voltammetry, charge capacitance, surface area

\section{Introduction}

The principal focus of modern research in electrocatalysis of SWNT-coated working electrode is to discover electrode materials that exhibit excellent electrochemical stability and show interesting activity towards electrochemical reactions. Our main attention is study of the electrochemical behavior of common

*e-mail: mmrahman@chonbuk.ac.kr electroactive species of $\mathrm{K}_{4} \mathrm{Fe}(\mathrm{CN})_{6}$ with SWNT-coated (physically modified) Gold and GC electrodes, and SWNT-film electrode directly immersed in the electrochemical solutions.

CNTs consisting of cylindrical graphitic sheets have emerged as a new class of materials with intriguing nanometer scale structures and unique properties, which attracted intensive attention in many fields such as nanoelectronic devices, composite materials, fieldemission devices, atomic force microscope probes, gas 
and chemical sensors, lithium ion storage. ${ }^{1-4}$ CNTs are generated by rolling a single or several layers of graphite into a seamless and hollow cylinder and can be divided into multi-walled carbon nanotubes $\left(\right.$ MWNTs $^{5}$ and single-walled carbon nanotubes (SWNTs) ${ }^{6}$ based on the number of carbon atom layers of the wall of the nanotubes. Since the discovery of CNTs by Iijima in 1991 using transmission electron microscopy, CNTs have been the subject of numerous investigations in chemical, physical and material areas due to their novel structural, mechanical, electronic and chemical properties. ${ }^{7-10}$ The subtle electronic properties confirmed that CNTs have the ability to promote electron-transfer reactions when used as an electrode in chemical reactions. ${ }^{11-14}$ Recent studies demonstrated that a CNT modified electrode could impart strong electrocatalytic activity to some important biomolecules, including cytochrome $c$, NADH and hydrogen peroxide, catecholamines such as dopamine, epinephrine, and ascorbic acid. ${ }^{15-17}$

From chemistry point of view, CNTs are expected to exhibit inherent electrochemical properties similar to other carbon electrodes widely used in various electrochemical applications. ${ }^{18}$ It is important to investigate fundamental electrochemical properties of CNT electrodes regarding background, capacitance, and electron transfer rate. Unlike other carbon-based nanomaterials such as $\mathrm{C}_{60}$ and $\mathrm{C}_{70}{ }^{19} \mathrm{CNTs}$ shows very different electrochemical properties. Liu et al. ${ }^{20}$ compared a single-walled carbon nanotubes film with that of $\mathrm{a}_{60}$ film cast in the same way from suspensions on a $\mathrm{Pt}$ or Au electrode. The cyclic voltammetry of SWNT-coated film showed a broad featureless curve with a large effective capacitance in contrast to that of the $\mathrm{C}_{60}$ film showing several pairs of discrete redox waves. Liu et al. ${ }^{20}$ attributed the featureless $\mathrm{CV}$ and large effective capacitance to two possibilities $(i)$ an average of many closely spaced peak corresponding to nanotubes with different length, diameter, and helicity, and (ii) CNTs behaving like bulk carbon materials with high effective surface area rather than individual redox active molecules. Even though the exact mechanism is not clear, the high specific capacitance was proposed for the application as supercapacitors. Barisci et al. ${ }^{21}$ investigated the capacitance behavior of SWNT electrodes and suggested that the large surface area and surface-surface bonded oxides are mainly responsible for the capacitance. The $\mathrm{Fe}(\mathrm{CN})_{6}{ }^{3-} / \mathrm{Fe}(\mathrm{CN})_{6}^{4-}$ couple was used as a benchmark to characterize the electron transfer properties of the SWNT-film and coated electrodes.
Because of CNTs novel structural and electronic properties, high chemical stability, and extremely high mechanical strength, which has become a major subject of many experimental and theoretical investigations, has a wide potential application from structural materials to nanoelectronic components. Theoretical calculations have shown that, depending on its symmetry and diameter, CNT can behave as either a metal or a semiconductor. ${ }^{22-24}$ Furthermore, it has been proved that CNT has better conductivity than graphite. ${ }^{25}$ Those results suggest that SWNT can be used as an electrode material and has ability to promote electron transfer in electrochemical reactions. This is a new application of SWNT and has received more and more attention. SWNT electrodes, particularly those never been used before SWNT-film as working electrode directly in electrochemical experiments, are often found to contain a thin paper film with the other electrode surface when submerged into the aqueous electrolyte solution. We found that the electrode properties are different due to the highly porous three-dimensional nature and the high hydrophobicity of the SWNT surface.

\section{Experimental}

\section{Instruments and chemicals}

All the electrochemical experimental observations are carried out with electrochemical analyzer BAS100B Potentiostat (USA) and SHIn EQCM (Korea). The active surface area of SWNT-coated GC and Gold electrodes are 0.027 and $0.26 \mathrm{~cm}^{2}$ respectively. All of the voltammetric measurements especially cyclic voltammetry are performed in a one compartment cell containing the SWNT-film or bare or SWNT-coated Gold (gold coated quartz crystal) or GC as a working electrode, a Pt wire as an auxiliary or counter electrode and a saturated $\mathrm{Ag} / \mathrm{AgCl}$ as a reference electrode. Cyclic voltammetry is performed at various concentration of $\mathrm{K}_{4} \mathrm{Fe}(\mathrm{CN})_{6}$ in $50 \mathrm{mmol} \mathrm{L}^{-1} \mathrm{KCl}$ working electrolytes with SWNT-film or SWNT-coated gold or GC electrode at various scan rates. The commercial SWNT dispersed solution is used for making SWNT-film electrode and SWNT-coated Gold or GC working electrode, which is obtained from Tubes@Rice company. $\mathrm{K}_{4} \mathrm{Fe}(\mathrm{CN})_{6}$ and $\mathrm{KCl}$ are used as received without further purification. Aqueous solutions are prepared with deionized water and other chemicals are used of reagent grade. A thin SWNT film is deposited by dropping of commercially dispersed SWNT solution on GC and Gold electrode surface and then heated with hot air. 
Preparation of the SWNT-coated and SWNT-film electrodes

The purification of common SWNTs is of great importance since most carbon nanotube applications require materials of high quality. Nitric acid is a common reagent for purification of carbon nanotubes and has constituted the first step in many different purification schemes. Nitric acid treatment is usually employed to remove metal catalysts, together with some of the amorphous carbon. ${ }^{26,27}$

The Glassy carbon electrode surface is cleaned with High purity Alumina powder (particle size, diameter $0.05 \mu \mathrm{m}$ ) to obtain a mirror-like, shiny electrode surface, and then washed with water. The gold-coated film electrode (10 MHz quartz crystal, ICM Co., OK, USA) is chemically cleaned in a Piranha solution ( $98 \% \mathrm{H}_{2} \mathrm{SO}_{4}$ and $30 \% \mathrm{H}_{2} \mathrm{O}_{2}, 2: 1$ by volume) under ultra-sonication. Tiny dropping of supplied commercial SWNT dispersed solution makes a thin-coated film. Few drops of SWNT solutions is placed onto the GC and Gold electrodes surface using a dropper and allowed to dry slowly and repeated one or two times more. The same coating procedure is repeated two or three times and then air dry at room temperature overnight to make SWNT-coated working GCE or Gold electrode. For SWNT-film electrode, the SWNT solution is separated from dispersed solvent by vacuum suction pump on PTFE (Polytetrafluroethylene) filter paper. Then the sample is dried overnight in an oven at temperature $60{ }^{\circ} \mathrm{C}$. After drying, the SWNT-film is automatically separated from PTFE filter paper. This lab made SWNTfilm is directly used as a working electrode through the total experiments. The thickness of SWNT-film is ca. $1 \mu \mathrm{m}$. The physical dimension of SWNT-film electrode is $47 \mathrm{~mm}$ (diameter of round thin paper), which automatically separated from filter paper.

SWNT-film electrode setting is shown in the schematic diagram bellow.

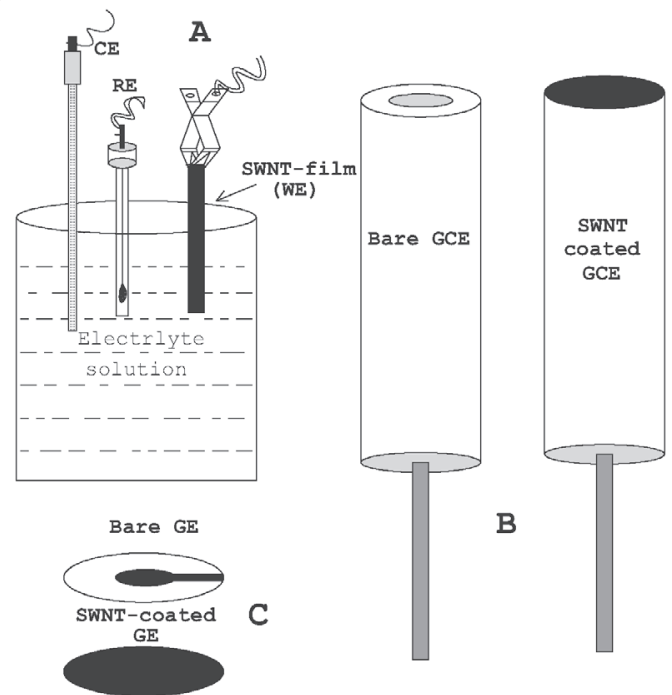

The setting of all working electrodes (SWNT-film, bare and SWNT-coated) are shown in schematic diagram.

\section{Results and Discussion}

The cyclic voltammetry is a versatile electroanalytical technique for the study of electroactive $\mathrm{K}_{4} \mathrm{Fe}(\mathrm{CN})_{6}$ species in three electrodes system. CV monitors redox behavior of chemical species within a wide potential range. The current at the working electrode is monitored as a triangular excitation potential is applied to the SWNTfilm or SWNT-coated gold or GC electrode. The resulting voltammogram can be analyzed for fundamental information regarding the redox reaction of electroactive components.

Cyclic voltammetry is conducted for five different types for electrodes: Bare GC, Bare Gold, SWNT-coated Gold, SWNT-coated GC, SWNT-film electrodes. The SWNT-film electrode exhibits the highest activity towards $\mathrm{K}_{4}\left[\mathrm{Fe}(\mathrm{CN})_{6}\right] / \mathrm{K}_{3}\left[\mathrm{Fe}(\mathrm{CN})_{6}\right]$ redox reactions as promising electrocatalytic materials.

\section{SWNT-coated gold electrodes}

The large effective charge capacitance of the SWNT electrode has been thoroughly investigated in simple supporting electrolyte $50 \mathrm{mmol} \mathrm{L}^{-1} \mathrm{KCl}$. To understand the electron-transfer property of these electrodes, $\mathrm{Fe}(\mathrm{CN})_{6}$ is introduced in the electrolyte as the redox benchmark in this study. Figure 1A shows CV obtained with bare gold (dotted line) and SWNT-coated gold (solid line) electrodes. The redox potential is measured for bare gold electrode at about +0.31 and $+0.13 \mathrm{~V}$, whereas +0.32 and $+0.11 \mathrm{~V}$ for SWNT-coated gold electrode. The peak separation is about $0.21 \mathrm{~V}$ for SWNT-coated gold electrode, which is larger than $0.18 \mathrm{~V}$ of bare gold electrode for ideal reversible one-electron-transfer reaction, indicating quasi-reversible processes between $\mathrm{Fe}(\mathrm{CN})_{6}{ }_{6}^{4} / \mathrm{Fe}(\mathrm{CN})_{6}^{3-}$ couple and the electrodes.

This indicates the larger effective surface area compared with the bare electrode. With the SWCNTcoated gold electrode, the peak height and the position of redox waves are significantly increased compared with bare gold system. The redox peak current is very stable through ten cycles (not shown) for SWNT-coated gold electrode in same electrochemical solutions at $0.1 \mathrm{Vs}^{-1}$ scan rate.

The cyclic voltammetry is also studied thoroughly at a series of scan rates ranging from 0.025 to $0.4 \mathrm{Vs}^{-1}$ in Figure 1B. The peak currents (anodic or cathodic) are is linearly increased with the square root of scan rates $(0.025$ 
to $0.4 \mathrm{Vs}^{-1}$ ) in Figure $1 \mathrm{C}$. The peak separation increases with the scan rate $\left(\Delta \mathrm{E}_{\mathrm{p}}=+0.21 \mathrm{~V}\right.$ at $0.1 \mathrm{Vs}^{-1}$ and $\Delta \mathrm{E}_{\mathrm{p}}=$ $+0.07 \mathrm{~V}$ at $\left.0.025 \mathrm{Vs}^{-1}, v s . \mathrm{Ag} \mid \mathrm{AgCl}\right)$ compared with bare gold electrode, indicating a quasi-reversible process likely as the result of both the slow electron transfer at the SWNT-surface (due to graphite basal plane-like structure) and the slow diffusion through the narrow pores.

Clearly, the peak current is almost linearly proportional to the square root of scan rate, indicating that the baseline
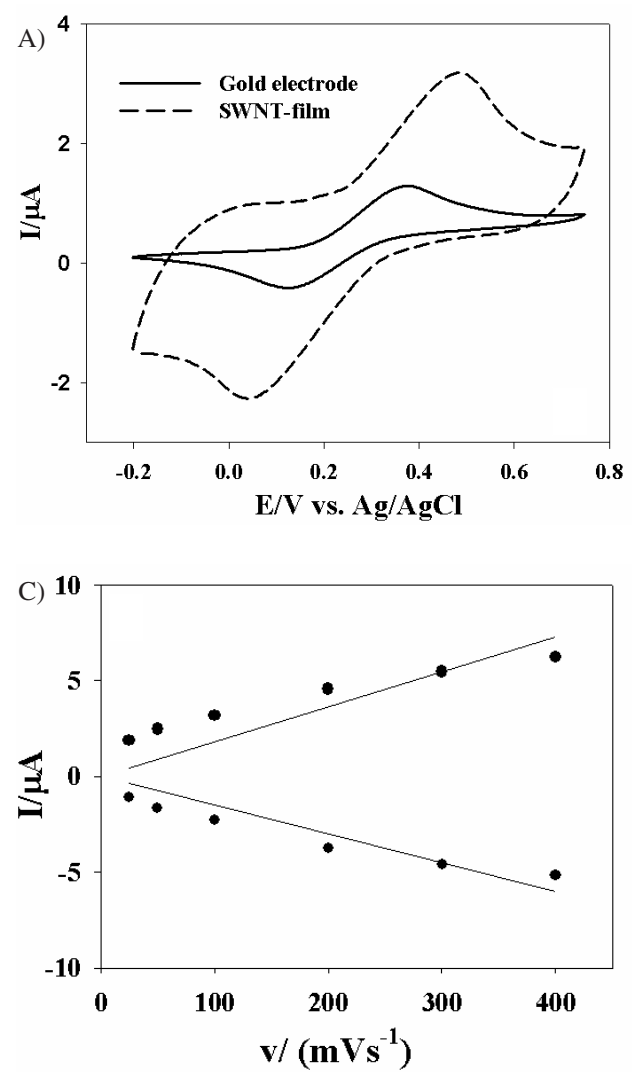

current corresponds to the capacitive charge current, Figure 1D. The current can be simply expressed as

$$
\mathrm{I}=\mathrm{C} \cdot \mathrm{dE} / \mathrm{dt}
$$

where, $\mathrm{dE} / \mathrm{dt}$ is the linear scan rate in $\mathrm{CV}$ measurements.

The capacitance could consists of two contributions:

(i) the capacitance due to the double-layer at the electrode/ electrolyte interface, which is proportional to the effective
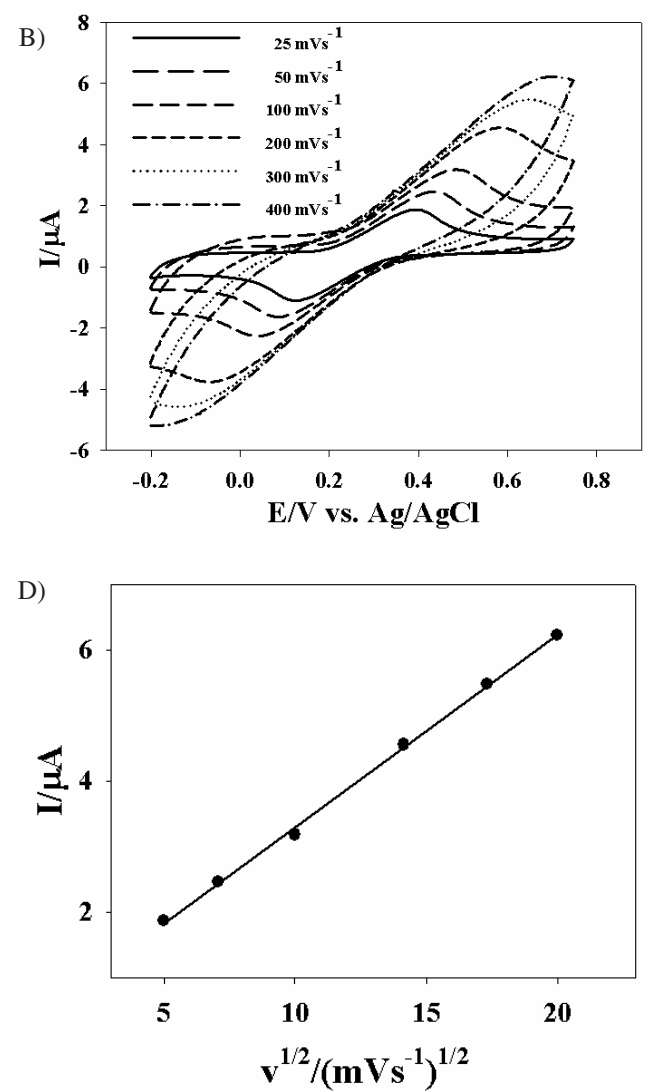

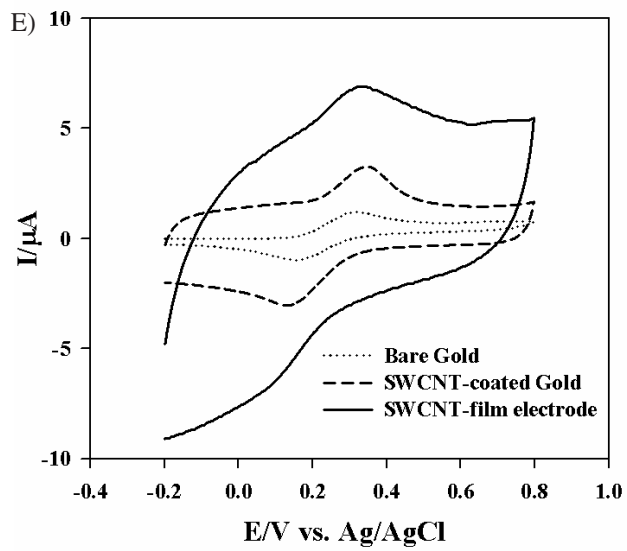

Figure 1. A) Cyclic voltammetry obtained with SWNT-coated (solid line) and bare gold electrodes (dotted line) in $5 \mathrm{mmol} \mathrm{L}^{-1} \mathrm{KCl}_{\text {electrolyte solution }}$ containing $4 \mathrm{mmol} \mathrm{L}^{-1} \mathrm{~K}_{4} \mathrm{Fe}(\mathrm{CN})_{6}$ at scan rate $100 \mathrm{mVs}^{-1}$. B) CV obtained for SWNT-coated gold electrode in same electrolyte solution at various scan rates range from $\mathrm{a}=25, \mathrm{~b}=50, \mathrm{c}=100, \mathrm{~d}=200, \mathrm{e}=300$ and $\mathrm{f}=400 \mathrm{mVs}^{-1}$ ). The peak current $v s$. the square root of scan rates plot is drawn in inset figure. C) Anodic current and cathodic current of the cyclic voltammetry obtained with SWNT-coated gold electrode $v s$. the scan rates. D) The fitted anodic peak height of the $[\mathrm{Fe}(\mathrm{CN})]^{4-} /[\mathrm{Fe}(\mathrm{CN})]^{3-}$ ion pair using SWNT-coated Au electrode vs. the square root of the scan rate. E) CV of SWNT-film electrode compared with the bare and SWNT-coated gold electrode in $50 \mathrm{mmol} \mathrm{L}^{-1} \mathrm{KCl}$ electrolyte solution containing $4 \mathrm{mmol} \mathrm{L}^{-1} \mathrm{~K}_{4} \mathrm{Fe}(\mathrm{CN})_{6}$ at $100 \mathrm{mVs}^{-1}$ scan rates. 
surface area and (ii) the "pseudocapacitance" due to the surface faradaic reaction of redox active oxides such as various quinones formed during the acid treatment in the sample preparation and purifications. ${ }^{28}$ The weak and broad oxidation wave around $+0.32 \mathrm{~V}$ and reduction wave around $+0.11 \mathrm{~V}$ are likely due to the later, similar to those observed by Barisci et al. ${ }^{21}$ This might be the reason that the effective capacitance below $+0.11 \mathrm{~V}$ is larger than that above $+0.32 \mathrm{~V}$. However, the pseudocapacitance only accounts for about one third of the observed value of the effective capacitance.

The double-layer capacitance is still the major component and can be used as a parameter to characterize the accessible surface area $\left(0.26 \mathrm{~cm}^{2}\right)$ in the porous SWNT materials. In Figure 1E; the redox current of SWNT-film electrode is clearly much bigger than that of the bare gold and SWNT-coated gold electrodes. The CV measurements with a various type electrodes indicate that the redox current is largely increased for SWNT-film electrodes. Since the both sides of thin nanotube film is a highly porous material, electrolytes likely access the interior surface. As a result, the volume of outer and inner surfaces of SWNT-film is considered for the charge capacitance, which is much more quite different from a simple bare gold electrode.

\section{SWNT-coated Glassy Carbon Electrodes (GCE)}

The same electrochemical strategy is used to compare the electrochemical behaviors of the GC working electrode with the different treatments. The same electrochemical investigations are carried out on $\mathrm{Fe}(\mathrm{CN}){ }_{6}^{4-} / \mathrm{Fe}(\mathrm{CN})_{6}{ }^{3-}$ couples for the SWNT-coated GC electrode, in order to find out the electrochemical behavior of the coated film and to obtain information related to the properties of this material. Dealing with this well-known redox couples $\mathrm{Fe}(\mathrm{CN})_{6}{ }^{4}-\mathrm{Fe}(\mathrm{CN})_{6}{ }_{6}^{3-}$, their electrochemical behavior can be used to characterize a new electrode material, with the aim of elucidating its properties. As compared to the voltammogram obtained at a bare GC electrode, SWNT-coated GC electrode showed a shift of oxidation/reduction peak to more negative/positive potentials respectively in Figure 2A. However, the observed current response is significantly higher and the shape of the peak is much better defined. The increased current is ascribed to the interaction of $\mathrm{K}_{4} \mathrm{Fe}(\mathrm{CN})_{6}$ complex with the coated SWNT on the electrode surface.

The CV curves of this compound are studied at various scan rates. It is found that the peak currents increase along with the rising of scan rate, while the
$\Delta E_{\mathrm{p}}$ expands gradually. At low scan rate, the cathodic peak current increases linearly with the increasing of square root of scan rates in Figure 2B, indicates that the redox reaction is a surface process. The complex/ SWNT-coated GC electrode has good stability and reproducibility. In the $\mathrm{CV}$ experiments, the reductive and oxidative peak currents are very stable through ten cycles in $4 \mathrm{mmol} \mathrm{L}^{-1} \mathrm{~K}_{4} \mathrm{Fe}(\mathrm{CN})_{6}$ and $50 \mathrm{mmol} \mathrm{L}^{-1} \mathrm{KCl}$. The influences of scan rate on the redox peak potential and current of $\mathrm{K}_{4} \mathrm{Fe}(\mathrm{CN})_{6}$ at SWNT-coated GC electrode are also studied by $\mathrm{CV}$. The results from $\mathrm{CV}$ showed that the redox peak current varies linearly with the scan rate, and also the oxidation and reduction potential shifts to more negative and positive values respectively with increasing scan rates. A plot of peak current (anodic or cathodic) against the square root of scan rate is almost a straight line (inset, Figure 2B).

The voltammograms obtained with the $\mathrm{Fe}(\mathrm{CN})_{6}{ }^{4-} /$ $\mathrm{Fe}(\mathrm{CN})_{6}^{3-}$ redox couple are shown in Figure 2C. It is important to note that although these redox couples are known to be quasi-reversible, the shape of the profiles depended on the surface conditions. The important observations can be summarized as follows: (i) An increase in current and the peak-to-peak potential when compared with the values on bare GC electrode; it is evident from the Figures that these changes not only depend on redox couple but also on the surface nature. (ii) The bare GC working electrode has shown a very little redox peak current during redox reactions when the compared to SWNT-coated electrode, it may be due to the enhancement of the surface area on coated GC electrode.

\section{SWNT-film electrodes}

It seems to be straight-forward to repeat the above measurements of $\mathrm{Fe}(\mathrm{CN})_{6}{ }^{4} / \mathrm{Fe}(\mathrm{CN}){ }_{6}{ }^{3-}$ couple with SWNTfilm electrodes. However it is too difficult to prepare thin paper like SWNT-film electrodes. The $\mathrm{Fe}(\mathrm{CN})_{6}^{4 / 3-}$ redox system used in this study is one of the most extensively studied redox couples in electrochemistry, exhibits a heterogeneous one electron transfer and very stable in many repeating cycles (Figure 3A). As the potential is scanned positively (forward scan) and is sufficient positive to oxidize $\mathrm{Fe}(\mathrm{CN})_{6}{ }^{4}$, the anodic current is due to the electrode processes and the electrode acts as an oxidant and the oxidation current increases to a peak. The concentration of $\mathrm{Fe}(\mathrm{CN})_{6}{ }^{4}$ at the SWNT-film electrode surface depletes and the current then decays. As the scan direction is switched to negative, for the reverse scan the potential is still sufficiently positive to oxidize $\mathrm{Fe}(\mathrm{CN})_{6}{ }_{6}^{4}$, 


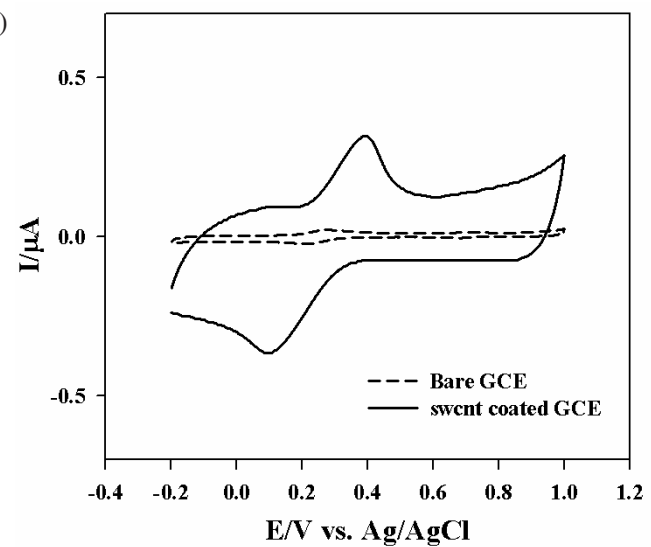

B)

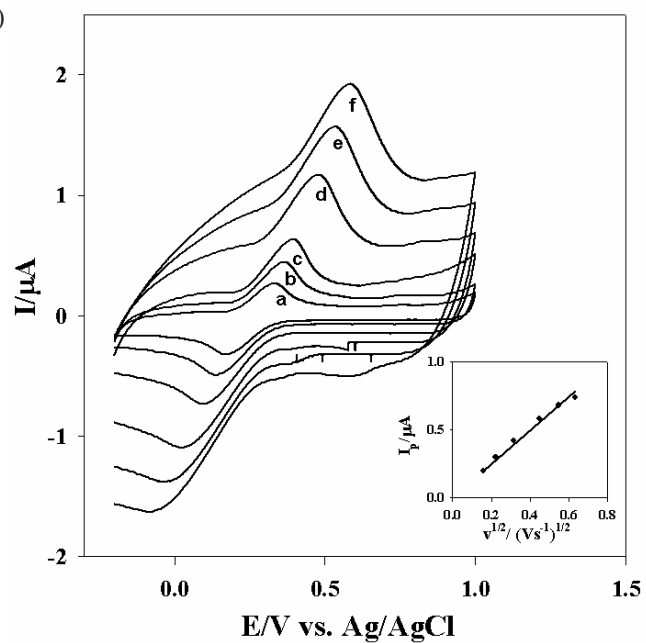

C)

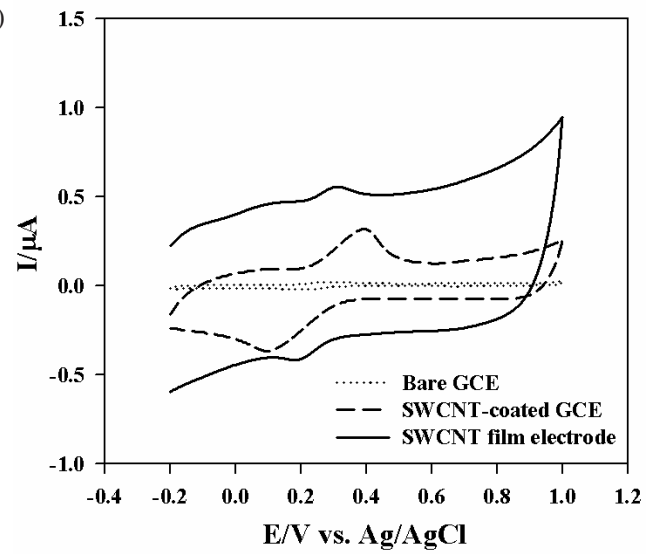

Figure 2. A) Bare \& SWNT-coated GC electrode at $100 \mathrm{mVs}^{-1}$ scan rate for $4 \mathrm{mmol} \mathrm{L}^{-1} \mathrm{~K}_{4} \mathrm{Fe}(\mathrm{CN})_{6}$ and $50 \mathrm{mmol} \mathrm{L}^{-1} \mathrm{KCl}$ electrolyte. B) SWNTcoated GCE used as working electrode at various scan rates $(\mathrm{a}=25, \mathrm{~b}=50$, $\mathrm{c}=100, \mathrm{~d}=200, \mathrm{e}=300$ and $\mathrm{f}=400 \mathrm{mVs}^{-1}$ ). Inset figure is drawn for Peak current $v s$. sq. root of scan rates. C) Comparative CV's of the Bare, SWNTcoated GCE with SWNT-film electrode.

so anodic current continues even though the potential is now scanning in the negative direction. When the electrode becomes a sufficiently strong reductant, $\mathrm{Fe}(\mathrm{CN})_{6}{ }^{3-}$, which has been forming adjacent to the electrode surface will be reduced by the electrode process.
With increasing scan rates, the anodic peak slightly shifted to the positive potential direction and the cathodic peak moved a little to the negative potential direction in Figure 3B. The peak current increases remarkably with increasing scan rates but the ratio of the anodic to cathodic peak currents $\left(\mathrm{I}_{\mathrm{a}} / \mathrm{I}\right)$ lies above unity. It indicates that the $\mathrm{Fe}(\mathrm{II})=\mathrm{Fe}(\mathrm{III})$ oxide transformation process is quasi-reversible. The variations of peak currents with changing scan rates from 0.025 to $0.5 \mathrm{Vs}^{-1}$ are investigated. It may be seen that both the anodic and cathodic peak currents $\left(I_{a}\right.$ and $I_{c}$ respectively) show a linear dependence with the series of square root of scan rates and passed almost through the origin in Figure 3C. Such behavior of peak current vs. square root of scan rates relationship generally appears in a quiescent solution in case of diffusion of an ionic species in the vicinity of the electrode surface, which defines the rate of the reaction. The peak current is increased greatly. The reason for the better performance of the SWNTfilm electrode may be due to the nanometer dimensions of the CNT, the electronic structure and the topological defects present on the CNT surfaces. Meanwhile the CNT increases the effective area of the electrode, so the peak current increases significantly.

The cyclic voltammetric experiments of the complex/ SWNT-coated GC electrode at different scan rate showed that the reductive and oxidative peak currents of complex were both linearly with the square root of scan rates $(v)$.

The SWNT-film shows better performance compared with SWNT-coated gold and GC electrodes. The SWNTfilm electrode can produce large capacitance; the later one is more suitable for applications in aqueous solutions. For three-dimensional surface areas, the total surface area includes both the surface of SWNTs interior of the film and that at the outer surface of the film. During synthesis of SWNT, it creates more oxide defects on the sidewalls and makes the SWNT-film more hydrophilic so that the aqueous solution can contact the surface better. As a result, the electron transfer rate can be improved.

Ajayan and co-workers ${ }^{30,31}$ used as initial densityfunctional-theory calculation and molecular dynamics simulations to study the microscopic mechanism of electron transfer on carbon nanotubes, they found that the improved activation behavior of oxygen reduction resulted from the dimensionality presence of topological defects in the lattices, which provided higher local electron density. Concretely, for this experiment, the surfaces of the single wall carbon nanotubes contain large numbers of defects, the pentagons at the nanotube tips, the pentagon-heptagon defect pairs in the lattice and the curvature contribute to the high surface activation, which 
A)

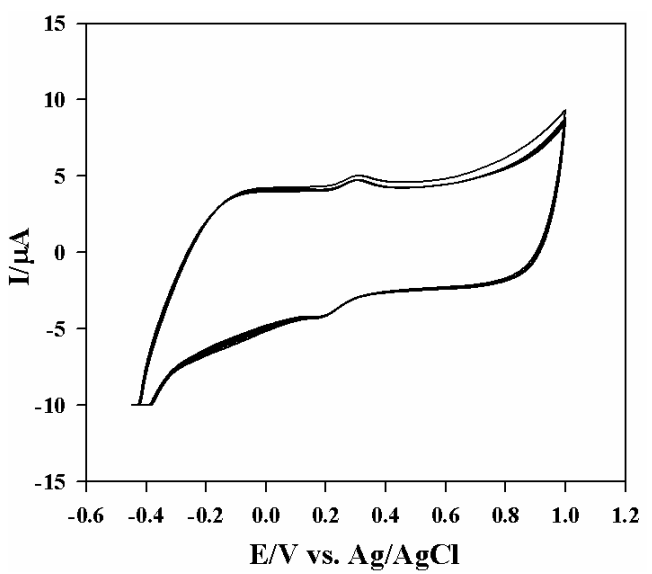

B)

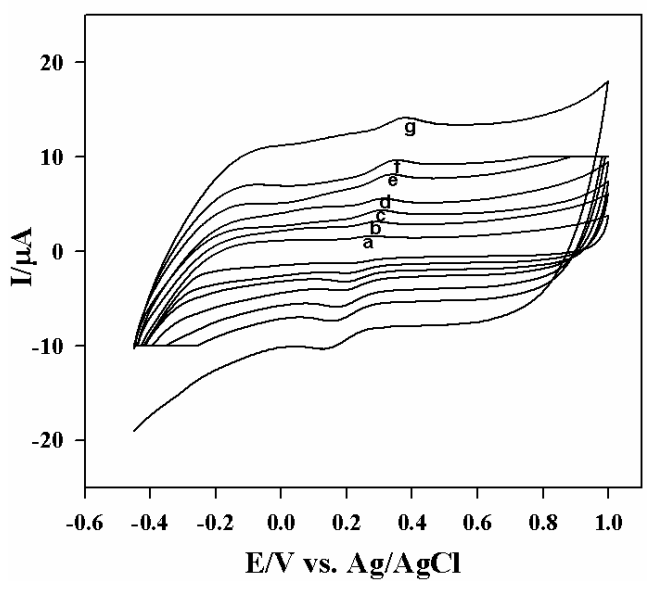

c)

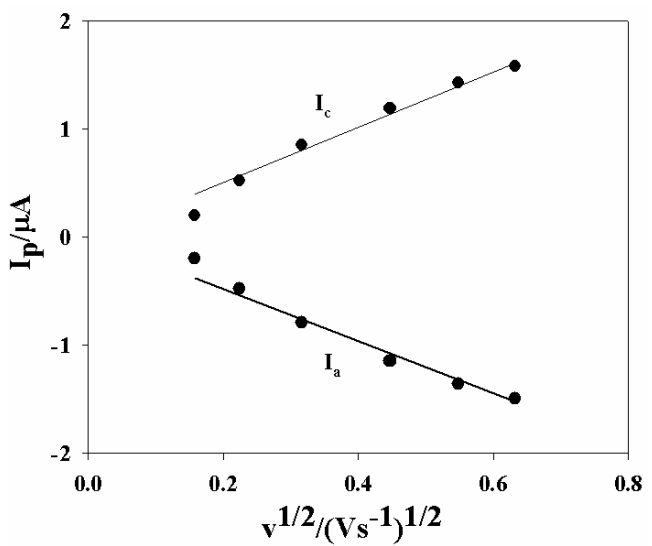

Figure 3. A) The thin film of SWNT used as working electrode (5 cycles) at $100 \mathrm{mVs}^{-1}$ scan rates. (Reaction conditions $4 \mathrm{mmol} \mathrm{L}^{-1} \mathrm{~K}_{4} \mathrm{Fe}(\mathrm{CN})_{6}$ and $50 \mathrm{mmol} \mathrm{L}^{-1} \mathrm{KCl}$ electrolyte). B) The thin film of SWNT (paper like) used as working electrode at different scan rates. $(a=25, b=50, c=100$, $\mathrm{d}=200, \mathrm{e}=300, \mathrm{f}=400$ and $\mathrm{g}=50 \mathrm{mVs}^{-1}$ ). C) Plot for peak currents [cathodic $\left(\mathrm{I}_{c}\right)$ and anodic $\left.\left(\mathrm{I}_{\mathrm{a}}\right)\right] v$ s. square root of scan rates. (Data abstracted same reaction condition as Figure 3B).

can benefit the electron transfer between the electrolyte solution and the nanotubes. On the other hand, the special nano-structure of SWNT maybe acts as "molecular wire" lead electrons to the redox centers of desired complex. Both the factors stand a good chance for resulting in the direct electron transfer of surface of SWNT, not at GC.
As summarized, we present the electrochemical characterization of three different types of carbon nanotube electrodes: SWNT-coated gold, SWNT-coated glassy carbon and SWNT-film electrodes. The electrochemical results reveal two type of informations: the capacitive current and the faradaic current due to the redox reaction of $\mathrm{Fe}(\mathrm{CN}){ }_{6}{ }^{4-} / \mathrm{Fe}(\mathrm{CN}){ }_{6}{ }^{3-}$ pairs presented in the solution. The capacitance indicates the change in total surface area as well as the density of surface oxides. For the three-dimensional structure, the total surface area includes both the surface of CNTs interior of the film and that at the outer surface of the film. The interior (and exterior) surface area of SWNTfilm is significantly exhibited redox catalytic properties in electrochemical investigations. So the redox reaction of $\mathrm{Fe}(\mathrm{CN}){ }_{6}{ }^{4-} / \mathrm{Fe}(\mathrm{CN})_{6}{ }^{3-}$ is found to occur not only at the outer surface of the SWNT-film but also interior of the film.

\section{Conclusions}

The electrochemistry of $\mathrm{K}_{4}\left[\mathrm{Fe}(\mathrm{CN})_{6}\right]$ is studied by cyclic voltammetry of SWNT-film, SWNT-coated Gold and SWNT-coated GC electrodes. A pair of well-defined redox waves is obtained. The peak currents of cyclic voltammetry increased linearly at different scan rates of $\mathrm{K}_{4}\left[\mathrm{Fe}(\mathrm{CN})_{6}\right]$ in scan rate 0.025 to $0.5 \mathrm{Vs}^{-1}$. The SWNT-film, SWNT-coated GC and Gold electrode exhibit remarkable electrocatalytic effect on the redox reaction of $\mathrm{K}_{4} \mathrm{Fe}(\mathrm{CN})_{6}$ and improving redox peak current. The SWNT provides many active sites, enhancing the sensitivity of $\mathrm{K}_{4} \mathrm{Fe}(\mathrm{CN})_{6}$ compound. Compared with the bare GC and Gold electrodes, the SWNT-coated electrodes show efficacy in detecting $\mathrm{K}_{4} \mathrm{Fe}(\mathrm{CN})_{6}$ redox peaks, exhibit excellent stability and reproducibility. We have illustrated that SWNT-film electrodes offer a stable and sensitive fixed-potential electrochemical detection of redox couples complexes. Further our efforts will aim at understanding better the mechanism of redox couples complexes at SWNTcoated electrodes. The effects of scan rate and the concentration change of $\mathrm{K}_{4} \mathrm{Fe}(\mathrm{CN})_{6}$ on the performance of the SWNT-film/coated/Gold/GC electrode are studied. The analysis of all results indicates that the electrode surface coated and thin-film by SWNT, the presence of holes, defects, charge capacity and their size and the possible interactions between the different species involved are the principal factors that determine the shapes of the voltammograms. Additionally, the dependence of the behavior of the couple on the electrode surface compositions is of great importance. 


\section{References}

1. Dresselhaus, M. S.; Dresselhaus, G.; Eklund, P. C.; Science of Fullerenes and Carbon Nanotubes; Academic Press: New York, 1996.

2. Ebbessen, T. W.; Carbon Nanotubes: Preparation and Properties; CRC Press: Boca Raton, FL, 1997.

3. Saito, R.; Dresselhaus, M. S.; Dresselhaus, G.; Physical Properties of Carbon Nanotubes; Imperial College Press: London, 1998.

4. Toma'nek, D.; Enbody, R.; Science and Application of Nanotubes; Kluwer Academic: New York, 2000.

5. Ijima, S.; Nature 1991, 354, 56.

6. Iijima S.; Ichihashi, T.; Nature 1993, 363, 603.

7. Baughrman, R. H.; Zakhidov, A. A.; Heer, W. A.; Science 2002, 297, 787.

8. Odom, T. W.; Huang, J. L.; Kim, P.; Lieber, C. M.; Nature 1998, 391, 62.

9. Jang, J. W.; Lee, D. K.; Lee, C. E.; Lee, T. J.; Lee, C. J.; Noh, S. J.; Solid State Commun. 2002, 122, 619.

10. Tekleab, D.; Czerw, R.; Carroll, D. L.; Ajayan, P. M.; Appl. Phys. Lett. 2000, 76, 3594.

11. Czerw, R.; Guo, Z.; Ajayan, P. M.; Sun, Y.-P.; Carroll, D. L.; Nano Letters 2001, 1, 423.

12. Davis, J. J.; Coles, R. J.; Hill, H. A.; J. Electroanal. Chem. 1997, 440, 279.

13. Luo, H.; Shi, Z.; Li, N.; Gu, Z.; Zhuang, Q.; Anal. Chem. 2001, $73,915$.

14. Wang, J.; Li, M.; Shi, Z.; Li, N.; Gu, Z.; Anal. Chem. 2002, 74, 1993.

15. Musamech, M.; Wang, J.; Merkoci, A.; Lin. Y.; Electrochem. Commun. 2002, 4, 743.

16. Wang, J.; Musameh, M.; Lin. Y.; J. Am. Chem. Soc. 2003, 125, 2408 .
17. Wang, J.; Musameh, M.; Anal. Chem. 2003, 75, 2075.

18. McCreery, R. L.; Electroanalytical Chemistry, Bard, A. J., ed.; Marcel Dekke: New York, 1991, vol. 17, p. 221.

19. Xie, Q.; Arias, J.; Echegoyen, L.; J. Am. Chem. Soc. 1993, 115, 9818.

20. Liu, C. Y.; Bard, A. J.; Wudl, F.; Weitz, I.; Heath, J. R.; Electrochem. Solid-State Lett. 1999, 2, 577.

21. Barisci, J. N.; Wallace, G. G.; Baughman, R. H. J.; Electrochem. Soc. 2000, 147, 4580.

22. Saito, R.; Fujita, M.; Dresselhaus, G.; Dresselhaus, M. S.; Appl. Phys. Lett. 1992, 60, 2447.

23. Wildöer, J. W. G.; Venema, L. C.; Rinzler, A. G.; Smalley, R. E.; Dekker, C.; Nature 1998, 391, 59.

24. Odom, T. W.; Huang, J. L.; Kim, P.; Lieber, C. M.; Nature 1998, $391,62$.

25. Pennisi, E.; Sci. News 1992, 142, 36.

26. Vaccarini, L.; Goze, C.; Aznar, R.; Micholet, V.; Journet, C.; Bernier, P.; Synth. Mat. 1999, 103, 2492.

27. Monthioux, M.; Smith, B. W.; Burteaux, B.; Claye, A.; Fischer, J. E.; Luzzi, D. E.; Carbon 2001, 39, 1251.

28. McCreery, R. L.; Electroanalytical Chemistry, Bard, A. J., ed.; Marcel Dekke: New York, 1991, vol. 17, p. 221.

29. Bachtold, A.; Henny, M.; Terrier, C.; Strunk, C.; Schonenberger, C.; Salvetat, J. P.; Bonard, J. M.; Forro, L.; App. Phys. Lett. 1998, 73, 274.

30. Britto, P. J.; Santhanam K. S. V.; Ajayan. P. M.; Bioelectrochem. Bioengin. 1996, 41, 121.

31. Britto, P. J.; Santhanam, K. S. V.; Rubio, A.; Alonso, J. A.; Ajayan,. P. M.; Adv. Mater. 1999, 11, 154.

Received: January 22, 2007 Web Release Date: September 4, 2007 